\title{
LOCALLY ADVANCED AND METASTATIC BREAST CANCER AT THE TIME OF PRESENTATION IN A PRIVATE HOSPITAL IN PESHAWAR.
}

MBBS, MRCS, FRCS

Fellow of Royal College of Surgeons Edinburgh, UK

Consultant

Oncoplastic Breast \& General Surgeon Rehman Medical Institute Peshawar, KPK.

Correspondence Address:

Dr. Amjad Ali

Oncoplastic Breast \& General Surgeon Rehman Medical Institute Peshawar, KPK.

dramjadali@gmail.com

Article received on: 08/03/2019

Accepted for publication: 27/06/2019

Received after proof reading: $30 / 09 / 2019$

\begin{abstract}
Amjad Ali ${ }^{1}$
ABSTRACT... Breast cancer is the most common cancer among women and Pakistan has the highest rate of breast cancers in Asia. Breast cancer patients present very late with their symptoms in Pakistan as compared to the developed world. As a result, our survival outcomes are very poor. Objectives: To estimate the frequency of breast cancer patients presenting with locally advanced and metastatic disease at presentation at our dedicated one-stop breast care unit (BCU) at Rehman Medical Institute Peshawar. Study Design: Observational study. Setting: Rehman Medical Institute Peshawar. Period: $1^{\text {st }}$ January 2018 to $31^{\text {st }}$ December 2018 . Material and Methods: Data was prospectively collected of all breast cancer patients presenting to BCU and recorded both electronically and in hard copy, and analysed. Results: A total of 83 patients were identified. $30 \%$ of the patients had metastatic disease at presentation while $34 \%$ had locally advanced disease. Only $36 \%$ had early breast cancer. Conclusion: This study supported the previously reported trend of very late presentation of patients with breast cancer in Pakistan.
\end{abstract}

Key words: $\quad$ Breast Cancer, Carcinoma, Malignancy, Metastatic Disease, Neoplasm.

Article Citation: Ali A. Locally advanced and metastatic breast cancer at the time of presentation in a major private hospital in Peshawar. Professional Med $\mathrm{J}$ 2019; 26(10):1693-1696. DOI: 10.29309/TPMJ/2019.26.10.3437

\section{INTRODUCTION}

Breast cancer is the most common cancer among women. ${ }^{1,2,3,4} 1$ in 8 women will develop breast cancer during her lifetime. Whilst there is no significant difference in the incidence of breast cancer worldwide, there is a huge difference in the survival outcomes. The low survival rate in the developing world is mainly due to the stage of the disease at the time of presentation. Studies have shown a much higher percentage of breast cancer patients in Pakistan to present with metastatic disease at the time of presentation and the peak incidence is reported to be in $40 s^{5}$ Due to the absence of early detection programmes, women generally present very late with symptoms of breast cancer in Pakistan. ${ }^{5}$ There is no national cancer registry in Pakistan at present and the only indications of regional variations in these statistics are the reported studies from individual hospitals. Data from KPK province regarding metastatic and locally advanced breast cancer cases is especially scarce. We present oneyear data of breast cancer cases in a dedicated one-stop breast care unit in Peshawar, KPK. Our objective was to find out the number/percentage of patients presenting with locally advanced and metastatic breast cancer and to see if there are any variations from the already reported statistics in Pakistan.

\section{METHODOLOGY}

\section{Inclusion Criteria}

All breast cancer patients presenting to our dedicated one-stop breast care unit during the year 2018 were included in this study.

\section{Exclusion Criteria}

Patients presenting with recurrent breast cancer, local or distant, were excluded. All the data was collected prospectively and recorded both electronically and in hard copy. Contrast CT of Thorax, Abdomen \& Pelvis along with Bone scan were used as staging investigations. Patients with T3 \& T4 tumors, more than 4 positive axillary nodes, positive axilla on preoperative 
assessment and inflammatory carcinoma of the breast underwent staging investigations. Study was conducted from $1^{\text {st }}$ January 2018 till $31^{\text {st }}$ December 2018.

\section{RESULTS}

A total of 83 patients were identified. Only $36 \%$ of the patients had early breast cancer. $34 \%$ had locally advanced and $30 \%$ had metastatic disease at presentation.

\section{Stage at presentation}

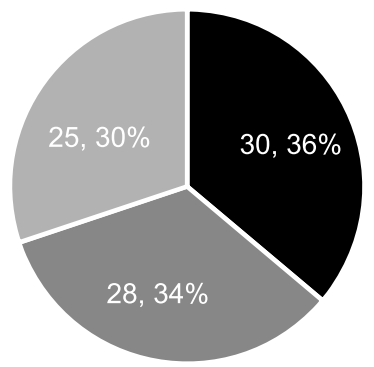

Early breast cancer $\square$ Locally advanced $\square$ Metastatic disease

Figure-1. Breast cancer stage at presentation

Further analysis showed a trend of younger patients presenting with breast cancer as compared to the developed world. Peak incidence in the west is reported to be around 60 year of age whilst our study showed an almost equal number of breast cancer patients in their 30s, 40s, 50s \& 60 s.

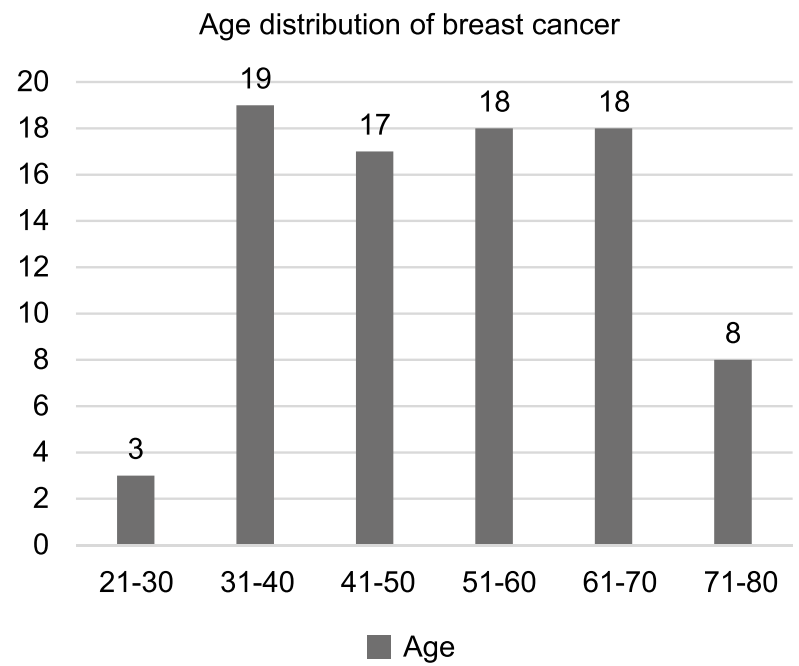

Figure-. 2 Age distribution of breast cancer

\begin{tabular}{|c|c|c|}
\hline Characteristics & $\begin{array}{c}\text { Patients } \\
\text { (Numbers) }\end{array}$ & $\begin{array}{c}\text { Patients } \\
\text { (Percentage) }\end{array}$ \\
\hline \multicolumn{3}{|l|}{ Age at Diagnosis } \\
\hline $21-30$ & 3 & 3.6 \\
\hline $31-40$ & 19 & 22.8 \\
\hline $41-59$ & 17 & 20.4 \\
\hline $51-60$ & 18 & 21.6 \\
\hline $61-70$ & 18 & 21.6 \\
\hline $71-80$ & 8 & 9.6 \\
\hline \multicolumn{3}{|l|}{ Gender } \\
\hline Male & 1 & 1.2 \\
\hline Female & 82 & 98.7 \\
\hline \multicolumn{3}{|l|}{ Presenting Symptom } \\
\hline Lump & 71 & 85.5 \\
\hline Ulcer & 7 & 8.4 \\
\hline Nipple Discharge & 3 & 3.6 \\
\hline Breast Pain & 2 & 2.4 \\
\hline \multicolumn{3}{|l|}{ Stage at Diagnosis } \\
\hline Early & 30 & 36.1 \\
\hline Locally advanced & 28 & 33.7 \\
\hline Metastatic & 25 & 30.1 \\
\hline \multicolumn{3}{|l|}{ Tumor Size } \\
\hline $\mathrm{T} 1(<2 \mathrm{~cm})$ & 8 & 9.6 \\
\hline T2 (2-5cm) & 32 & 38.5 \\
\hline T3 $(>5 \mathrm{~cm})$ & 19 & 22.9 \\
\hline $\begin{array}{l}\text { T4 (involving skin Or } \\
\text { chest wall) }\end{array}$ & 18 & 21.6 \\
\hline $\mathrm{N} / \mathrm{A}$ & 6 & 7.2 \\
\hline \multicolumn{3}{|l|}{ Nodal Status } \\
\hline No (0 nodes +ve) & 22 & 26.5 \\
\hline N1 (1-3 nodes +ve) & 16 & 19.2 \\
\hline N2 (4-9 nodes +ve) & 7 & 8.4 \\
\hline N3 (>9 nodes +ve) & 32 & 38.5 \\
\hline $\mathrm{N} / \mathrm{A}$ & 6 & 7.2 \\
\hline \multicolumn{3}{|l|}{ Metastasis } \\
\hline M0 (No Metastasis) & 50 & 60.2 \\
\hline M1 (Metastasis Present) & 25 & 30.1 \\
\hline $\mathrm{N} / \mathrm{A}$ & 8 & 9.6 \\
\hline \multicolumn{3}{|l|}{ Type of Cancer } \\
\hline In-situ & 2 & 2.4 \\
\hline Invasive Ductal & 59 & 71 \\
\hline Invasive Lobular & 4 & 4.8 \\
\hline Medullary & 1 & 1.2 \\
\hline Mucinous & 3 & 3.6 \\
\hline Metaplastic & 2 & 2.4 \\
\hline Papillary & 1 & 1.2 \\
\hline Leiomyosarcoma & 1 & 1.2 \\
\hline $\mathrm{N} / \mathrm{A}$ & 10 & 12 \\
\hline \multicolumn{3}{|l|}{ Grade of Cancer } \\
\hline 1 & 12 & 14.4 \\
\hline 2 & 33 & 39.7 \\
\hline 3 & 24 & 28.9 \\
\hline $\mathrm{N} / \mathrm{A}$ & 14 & 16.8 \\
\hline \multicolumn{3}{|l|}{ Estrogen Receptor } \\
\hline Positive & 39 & 46.98 \\
\hline Negative & 18 & 21.6 \\
\hline $\mathrm{N} / \mathrm{A}$ & 26 & 31.3 \\
\hline \multicolumn{3}{|l|}{ HER2 Receptor } \\
\hline Positive & 18 & 21.6 \\
\hline Negative & 28 & 33.7 \\
\hline Equivocal & 11 & 13.2 \\
\hline $\mathrm{N} / \mathrm{A}$ & 26 & 31.3 \\
\hline
\end{tabular}

Professional Med J 2019;26(10):1693-1696. 
Only one of 83 patients was a male and the rest were all females. Breast lump was the most common (85\%) presenting symptom. Locally advanced and metastatic tumors accounted for $64 \%$ of cases. Subgroup analysis showed only $9.6 \%$ of patients presenting with small T1 tumors and a combined $44 \%$ patients presenting with tumors larger than $5 \mathrm{~cm}$ or invading the chest wall or skin at the time of diagnosis (Table-I). Invasive ductal variety was the most common type of breast cancer. ${ }^{6}$ There was a similar trend in nodal status with a combined $66 \%$ patients having axillary lymph node involvement at the time of presentation. In addition, distant metastasis was present in $30 \%$ of the cases at diagnosis. Majority of the tumors were invasive ductal and of higher grade (2\&3). $47 \%$ of the tumors were estrogen receptor positive and $21 \%$ showed HER2 positivity. $31 \%$ of the patients underwent breast conservation surgery whilst $67 \%$ had mastectomy.

\section{DISCUSSION}

American Joint Committee for Cancer defines locally advanced breast cancer as a tumor size of greater than $5 \mathrm{~cm}$, tumor involving skin or chest wall or positive axilla with more than 3 involved nodes in the absence of distant metastatic disease. And metastatic breast cancer by definition is incurable. ${ }^{7}$ Our study showed $30 \%$ of patients presenting with metastatic disease at the time of the diagnosis whilst $34 \%$ had locally advanced disease. Soomro et $\mathrm{al}^{5}$ retrospectively looked into 10,018 breast cancer patients in a tertiary care center in Karachi Pakistan and reported $28 \%$ of patients to have metastatic disease at presentation which is comparable to our study. This is also concordant with other studies reporting stage 3 and 4 disease at presentation of over $50 \% .^{8,9}$ Concord study ${ }^{12}$ looked at 20,000 breast cancer patients in 7 US states and 12 European countries. This showed $8 \%$ of the patients presenting with locally advanced disease in European countries and $4 \%$ in the US. Patients presenting with metastatic disease were similar in number in US and Europe (5-6\%).

Our study showed a much higher incidence of breast cancer in the $3^{\text {rd }}$ and $4^{\text {th }}$ decade of life compared to breast cancer patients in the west. This is comparable to the data published by Shaukat Khanum Memorial Cancer Research Hospital and Soomro et al.

Studies have shown a significant increase in the detection of breast cancer at in-situ stage after the breast screening programmes. ${ }^{10}$ Before the breast screening programmes, only $2 \%$ of all breast cancer detected was in-situ disease, as our study has shown. With comprehensive breast screening programmes around the world, $20 \%$ of all screen detected cancers are at in-situ stage which has an excellent prognosis.

Tumor size and lymph node status have significant impact on survival. ${ }^{11}$ Concord study also concluded that the number of patients presenting with locally advanced and metastatic disease is directly related to absence of screening programmes and low socio-economic status. 5-year survival for such patients is reported to be around $48-52 \% .^{12}$

Lack of a comprehensive breast screening programme in Pakistan explains all these statistics. Studies have shown breast screening to reduce breast cancer mortality significantly. ${ }^{13}$ A much higher percentage of patients presenting with locally advanced and metastatic disease is in line with absence of a breast screening programme as is the very low percentage of breast cancer diagnosed at in-situ stage. Breast cancer survival is directly related to the stage of the disease at presentation. Previously reported 5-year survival of breast cancer patients in Pakistan of around $50 \%$ is also reflective of the advanced stage of breast cancer at presentation. We need more studies with bigger sample size to further validate these results and make a stronger case for having a comprehensive breast screening programme in Pakistan.

The most common presentation of breast cancer in our study was a lump (85\%). Memon ZA reported a similar number of patients (77\%) of breast cancer presenting with a lump (14). Among symptomatic patients, this is comparable worldwide. 


\section{CONCLUSION}

Our study supported the previously reported much higher percentage of breast cancer patients presenting at locally advanced and metastatic stage in Pakistan as compared to the developed world. Majority of breast cancer patients in Pakistan present at a much younger age with peak incidence approximately 10 years lower than the west.

Copyright@ 27 June, 2019.

\section{REFERENCES}

1. Asif HM, Sultana S, Akhtar N, Rehman JU, Rehman RU. Prevalence, risk factors and disease knowledge of breast cancer in Pakistan. Asian Pac J Cancer Prev. 2014; 15(11):4411-6.

2. Basra MA, Saher M, Athar MM, Raza MH. Breast cancer in Pakistan a critical appraisal of the situation regarding female health and where the nation stands? Asian Pac J Cancer Prev. 2016; 17(7):3035-41.

3. Hussain A, Ahmad SB, Muhammad W, Kakakhail MB, Matiullah. Epidemiology of the breast cancer patients registered at Institute of radiotherapy and nuclear medicine, peshawar, Pakistan. Eur J Cancer Care (Engl). 2008; 17(5):469-76.

4. Arif $M$, Raza $H$, Sohail Afzal M. Alarming situation of breast cancer in women of Lahore, Pakistan From 1984 to 2018. Breast Cancer (Auckl). 2018; 12:1178223418816093.

5. Soomro R, Faridi S, Khurshaidi N, Zahid N, Mamshad I. Age and stage of breast cancer in Pakistan: An experience at a tertiary care center. J Pak Med Assoc. 2018; 68(11):1682-5.

6. Afsar NA, Kulsoom B, Mateen A, Ahmed S, Tahseen M, Ahmed $A$. Breast cancer pattern and chemotherapy response--an institutional study in Pakistan. Asian Pac J Cancer Prev. 2010; 11(3):825-30.
7. De Luca R, Profita G, Cicero G. Nab-paclitaxel in pretreated metastatic breast cancer: Evaluation of activity, safety, and quality of life. Onco Targets Ther. 2019; 12:1621-7.

8. Ahmed F, Mahmud S, Hatcher J, Khan SM. Breast cancer risk factor knowledge among nurses in teaching hospitals of Karachi, Pakistan: A crosssectional study. BMC Nurs. 2006; 5:6.

9. Gilani GM, Kamal S, Akhter AS. A differential study of breast cancer patients in Punjab, Pakistan. J Pak Med Assoc. 2003; 53(10):478-81.

10. Theberge I, Vandal N, Guertin MH, Perron L. The mammography screening detection of ductal carcinoma in situ and invasive breast cancer according to women's characteristics: Is it the same? Breast Cancer Res Treat. 2019; 174(2):525-35.

11. Mahmood H, Faheem M, Mahmood S, Sadiq M, Irfan J. Impact of age, tumor size, lymph node metastasis, stage, receptor status and menopausal status on overall survival of breast cancer patients in Pakistan. Asian Pac J Cancer Prev. 2015; 16(3):1019-24.

12. Allemani C, Sant M, Weir HK, Richardson LC, Baili P, Storm $H$, et al. Breast cancer survival in the US and Europe: A concord high-resolution study. Int J Cancer. 2013; 132(5):1170-81.

13. Giannakeas $V$, Narod SA. The incidence of fatal breast cancer measures the increased effectiveness of therapy in women participating in mammography screening. Cancer. 2019.

14. Memon ZA' ${ }^{1}$, Qurrat-ul-Ain, Khan R, Raza N, Noor T. Clinical presentation and frequency of risk factors in patients with breast carcinoma in Pakistan. Asian Pac J Cancer Prev. 2015; 16(17):7467-72.

\section{AUTHORSHIP AND CONTRIBUTION DECLARATION}

\begin{tabular}{|c|c|c|}
\hline Sr. \# & Author-s Full Name & \multicolumn{1}{c|}{ Contribution to the paper } \\
\hline 1 & Amjad Ali & $\begin{array}{l}\text { Study design, Data collection, } \\
\text { Analysis, Writing, Llterature } \\
\text { search. }\end{array}$ \\
\hline
\end{tabular}

